\title{
APLIKASI INVERTORY YANG TERINTEGRASI DENGAN INVENTARIS BARANG MENGGUNAKAN BARCODE SCANNER BERBASIS WEB
}

(Studi Kasus Fakultas Ilmu Komputer Universitas Kuningan)

\author{
Endra Suseno ${ }^{1}$, Sherly Gina Supratman ${ }^{2}$ \\ ${ }^{1}$ Sistem Informasi Fakultas Ilmu Komputer, Universitas Kuningan \\ ${ }^{2}$ Teknik Informatika Fakultas Ilmu Komputer, Universitas Kuningan \\ Email :1endra@uniku.ac.id, ${ }^{2}$ sherly.gina.supratman@uniku.ac.id
}

\begin{abstract}
Abstrak
Proses penyediaan alat di lingkungan universitas kuningan masih dilakukan secara manual, yaitu dengan menulis barang atau alat apa saja yang dibutuhkan oleh setiap unit, satuan tugas yang diajukan kepada bidang sarana dan prasarana yang dikelola oleh Universitas. Penelitian ini dilakukan untuk merancang dan membuat serta menerapkan sistem inventori yang terintegrasi dengan inventaris barang dengan menggunakan barcode scanner dengan memanfaatkan media jaringan web, sehingga hasil pembacaan scanner dapat diolah oleh aplikasi inventori melalui PC yang terhubung dengan jaringan workstation disetiap unit tugas yang ada di Universitas Kuningan. Pengembangan sistem inventori terintegrasi dengan inventaris barang menggunakan metode pengembangan aplikasi RUP (Rational Unified Process). Rational Unified Process merupakan suatu metode rekayasa perangkat lunak yang dikembangkan Dengan menggunakan konsep object oriented, dengan aktifitas yang berfokus pada pengembangan model dengan menggunakan Unified Model Language (UML). Pada sistem inventeris dan inventory terdapat tiga actor yaitu manajemen dan pelaksana. Aktor yaitu sebagai manajemen yang merupakan penyedia yang sudah terdaftar didalam sistem yang memiliki hak akses secara penuh untuk mengelola data monitoring dan laporan data barang secara berkala. Sedangkan dua actor yang selain sebagai pengguna yang memiliki hak akses terbatas sesuai dengan kebutuhannya.Pada actor pengguna terdapat actor turunan yang menjadi pengguna dalam system, dikarenakan yang terdaftar dalam aplikasi adalah fakultas.
\end{abstract}

Kata kunci : aplikasi inventory dan inventaris berbasis web

\begin{abstract}
The process of providing tools in the Kuningan university environment is still done manually, namely by writing what items or tools are needed by each unit, the task force is submitted to the field of facilities and infrastructure managed by the University. This research was conducted to design and create and implement an integrated inventory system with inventory using barcode scanners using web network media, so that the scanner readings can be processed by the inventory application via a PC connected to a network of workstations in each task force at Kuningan University. . The development of an integrated inventory system with inventory of goods uses the RUP (Rational Unified Process) application development method. Rational Unified Processis a software engineering method developedWithusing the concept of object oriented, with activities that focus on developing models using the Unified Model Language (UML). In the inventory and inventory system, there are three actors, namely management and executor. The actor is a management who is a registered provider in the system who has full access rights to manage monitoring data and report goods data periodically. Meanwhile, two actors are not only users who have limited access rights according to their needs. In user
\end{abstract}


JURNAL NUANSA INFORMATIKA

Volume 15 Nomor 1, Januari 2021
p-ISSN : 1858-3911, e-ISSN : 2614-5405

https://journal.uniku.ac.id/index.php/ilkom

actors, there are derivative actors who become users of the system, because those listed in the application are faculties.

Keyword: web base inventory aplication

\section{PENDAHULUAN}

Perkembangan teknologi di dunia semakin pesat baik itu hardware maupun software, khususnya kemajuan di bidang teknologi informasi terutama pada teknologi mobile dan internet. Penggunaan aplikasi mobile dan web dikatakan lebih efektif dan efisien karena adanya kemudahan dalam pengaksesan dan pengambilan informasi.

Perkembangan teknologi hardware juga sangat berpengaruh terhadap input, proses, dan output

yang dilakukan terhadap suatu sistem. Seperti teknologi hardware berupa piranti input seperti aplikasi yang dapat memberikan kemudahan input bahkan validasi input yang sangat akurat yang bisa digunakan dalam proses inventaris. Dengan teknologi input data, dapat meminimalisir kesalahan input bahkan keterlambatan input ke sistem.

\section{METODE PENELITIAN}

\subsection{Analisis data}

Dari hasil wawancara, yang dilakukan dapat diketahui bahwa :

1. Pendataan barang inventaris disimpan pada computer offline dalam format worksheet excel, dengan demikian data yang dimiliki tidak dapat diakses oleh unit lain selain bagian sarpras.

2. Jika unit membutuhkan data tersebut wajib datang dan membawa media penyimpanan dan dicopy kedalam media penyimpanan.

3. Pada tahap awal diperlukan pengembangan aplikasi yang dapat diakses oleh setiap unit tugas yang ada dilingkungan Universitas Kuningan
Data primer berupa data inventaris barang yang dimiliki oleh bagian sarpras dalam bentuk format woksheet. Disajikan pada gambar 1 .

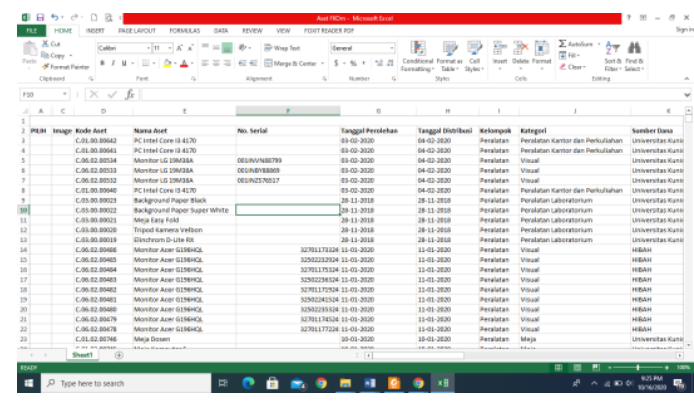

Gambar 1 Aset barang Fakultas Ilmu Komputer

Dari hasil observasi tersebut dibutuhkan pengembangan dengan menggunakan teknologi yang tepat agar dapat mempermudah, diantaranya adalah dengan mengembangkan aplikasi inventori terintegrasi dengan inventaris barang menggunakan barcode scanner.

\subsection{Data observasi}

Observasi data dilakukan untuk mengidentifikasi masalah-masalah yang akan muncul dalam pembuatan sistem, dilakukan saat tahap analisa, perancangan data, mengimplementasikan sistem serta menguji dan menganalisis hasil implementasi dari sistem sehingga sistem dapat berjalan dengan baik sesuai dengan yang telah ditetapkan.[1].

\subsection{Perancangan Aristektur aplikasi} Berdasarkan kegiatan hasil wawancara dan observasi yang telah dilakukan maka secara garis besar dapat digambarkan perancangan arsitektur aplikasi yang akan dikembangkan pada gambar 2 . 


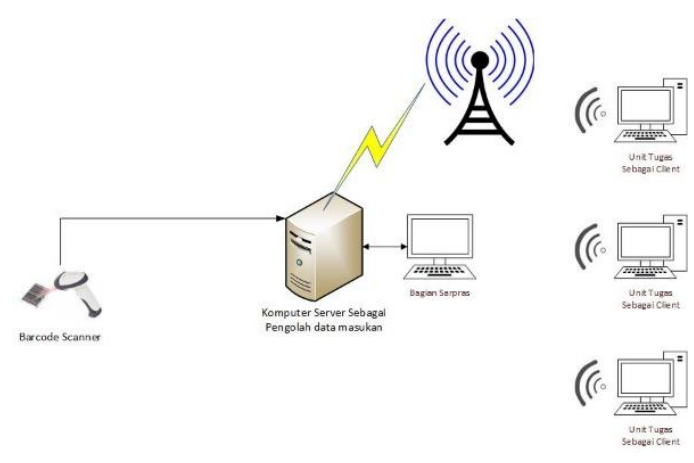

Gambar 2 arsitektur aplikasi

Secara garis besar aplikasi yang dikembangkan terdiri dari tiga aktivitas

- Kode barcode sebagai objek yang akan digunakan sebagai pengganti kode barang

- Barcode Scanner sebagai alat perekam dan pencariannya

- Server sebagai pusat penyimpanan dan pengolahan data terhadap barang inventaris

Pada ranncangan aplikasi yang dikembangkan pada gambar 3 secara teknis meliputi kegiatan-kegiatan sebagai berikut:

- Aplikasi yang dikembangkan adalah aplikasi berbasis web.

- Alat bantu yang akan digunakan yang merupakan media pencarian menggunakan barcode scanner.

- Penyinaran kode yang bergantung pada jarak dan sudut penyinaran merupakan factor utama dalam pengenalan kode barang yang akan direkam

- Computer server merupakan tempat penyimpanan dan pengolahan data yang dapat digunakan dalam perekaman kode barang.

- Proses perekaman data melalui alat scanner membutuhkan koneksi yang secara terus menerus dan simultan yang menghubungkan antar perangkat yang digunakan.[2]
p-ISSN : 1858-3911, e-ISSN : 2614-5405

https://journal.uniku.ac.id/index.php/ilkom

\section{HASIL DAN PEMBAHASAN}

3.1 Metode pengembangan sistem

Rational Unified Process merupakan suatu metode rekayasa perangkat lunak yang dikembangkan dengan mengumpulkan berbagai best practises yang terdapat dalam industri pengembangan perangkat lunak. Ciri utama metode ini adalah menggunakan use-case driven dan pendekatan iteratif untuk siklus pengembangan perankat lunak. RUP menggunakan konsep object oriented, dengan aktifitas yang berfokus pada pengembangan model dengan menggunakan Unified Model Language (UML).[3] UML (Unified Modeling Language) adalah 'bahasa' pemodelan untuk sistem atau perangkat lunak yang berparadigma 'berorientasi objek". Pemodelan (modeling) sesungguhnya digunakan untuk penyederhanaan permasalahan-permasalahan yang kompleks sedemikian rupa sehingga lebih mudah dipelajari dan dipahami dapat lihat pada gambar 4

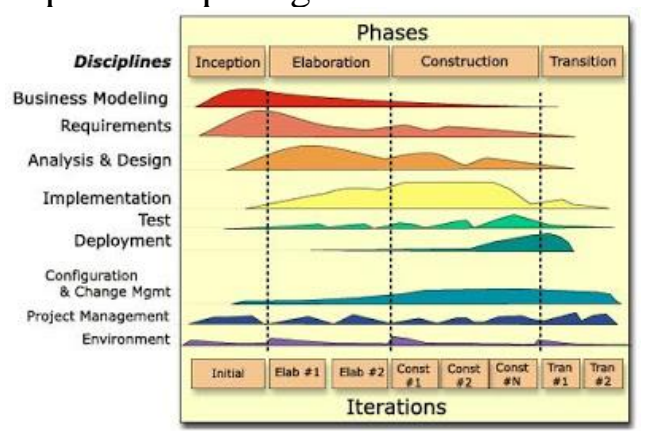

Gambar 3 Fase $R U P$

Terdapat 4 tahapan dalam fase RUP yaitu

1. Tahap Inception

Pelaksanaan tahap inception dilakukan proses pengimpulan data yaitu proses identifikasi serta menspesifikasiakan kebutuhankebutuhan data secara umum terkait sistem yang akan dikembangkan. Hasil dari kegiatan analisis ini menghasilkan spesifikasi-spesifikasi dari karakteristik-karakteristik data operasional yang akan dimiliki oleh 
JURNAL NUANSA INFORMATIKA

Volume 15 Nomor 1, Januari 2021

system perangkat lunak yang akan dikembangkan dalam penelitian ini. Juga mengidentifikasi rancangan perangkat lunak dengan elemenelemen sistem yang lain, serta menetapkan batasan-batasan yang harus dihadapi sistem.

Dalam tahapan inception data yang didapatkan akan disesuaikan dengan konversi kode barcode dengan cara melihat kode inventaris yang telah diberikan hasil konversi kode inventaris akan diubah kedalam kode biner dan bar.

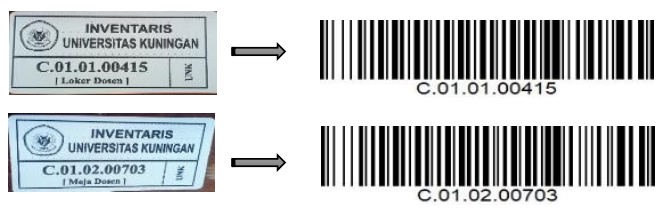

Gambar 4 konversi kode barcode

1. Hasil konversi

Dari hasil percobaan mengkonversi kode inventaris manual kedalam format barcode ternyata berhasil dimana pada saat akan dikonversi harus menentukan basis pengkodeannya pada percobaan ini digunakan basis Linier Code dengan type Code-128, type Code-128 dapat menerima bentuk kode yang memiliki composit type data. Informasi pada Barcode berisi enkripsi dari sejumlah digitangka. Saat barcode tersebut di scan dengan alat barcode scanner, maka kode tersebut secara otomatis terhubung ke data barang yang sudah disimpan dalam database [4]

Berdasarkan hasil konversi pada gambar 1 maka dapat dijelaskan bahwa hasil konversi kode barcode yang dihasilkan akan menentukan teknis dari system yang akan dikembangkan dalam penelitian ini yaitu:
p-ISSN : 1858-3911, e-ISSN : 2614-5405

https://journal.uniku.ac.id/index.php/ilkom

- Aplikasi yang akan dikembangkan adalah aplikasi pembacaan kode barcode yang merupakan objek benda yang akan dikelola

- Setiap kode yang ada pada barang inventaris akan dikelompokan dalam beberapa kelompok sesuai dengan jenis barang

- Hasil pembacaan akan dilakukan melalui sebuah perangkat khusus yang dapat membaca kode bar yang ada pada barcode.

- Hasil pembacaan kode bar akan diteruskan ke server

- Komunikasi data antar perangkat yang terhubung akan dilakukan secara terus-menerus Agar tidak terjadi kesalahan dalam membaca kode barcode, penentuan jarak baca menjadi penting karena akan

- mempengaruhi keakuratan pembacaan kode barcode.

Pengujian jarak dan sudut yang dapat di baca oleh scanner barcode pada kode barcode inventaris barang, disajikan pada table 1 .

Table 1 data pengujian pembacaan barcode

\begin{tabular}{|c|c|c|c|c|c|}
\hline \multirow[t]{3}{*}{$\begin{array}{l}\text { Sample } \\
\text { barcode }\end{array}$} & $\begin{array}{c}\text { Jara } \\
\mathrm{k} \\
\text { dala } \\
\mathrm{m} \\
(\mathrm{cm})\end{array}$ & \multicolumn{4}{|c|}{$\begin{array}{l}\text { Sudut dalam ( } \\
\left.\qquad 0^{0}\right)\end{array}$} \\
\hline & & 3 & 4 & 6 & 9 \\
\hline & & 0 & 5 & 0 & 0 \\
\hline $\begin{array}{c}\text { C.00.02.001 } \\
43\end{array}$ & 0 & $\mathrm{x}$ & $\mathrm{X}$ & $\mathrm{x}$ & $\mathrm{x}$ \\
\hline $\begin{array}{c}\text { C.00.02.001 } \\
43\end{array}$ & 1 & $\mathrm{X}$ & $\mathrm{X}$ & $\mathrm{X}$ & $\mathrm{X}$ \\
\hline $\begin{array}{c}\text { C.00.02.001 } \\
43\end{array}$ & 2 & $\mathrm{X}$ & $\mathrm{X}$ & $\mathrm{X}$ & $\mathrm{X}$ \\
\hline $\begin{array}{c}\text { C.00.02.001 } \\
43\end{array}$ & 3 & $\mathrm{X}$ & $\mathrm{X}$ & $\sqrt{ }$ & $\sqrt{ }$ \\
\hline $\begin{array}{c}\text { C.00.02.001 } \\
43\end{array}$ & 4 & $\sqrt{ }$ & $\sqrt{ }$ & $\sqrt{ }$ & $\sqrt{ }$ \\
\hline $\begin{array}{c}\text { C.00.02.001 } \\
43\end{array}$ & 5 & $\sqrt{ }$ & $v$ & $\sqrt{ }$ & $\sqrt{ }$ \\
\hline
\end{tabular}


JURNAL NUANSA INFORMATIKA

Volume 15 Nomor 1, Januari 2021

\begin{tabular}{|c|c|c|c|c|c|}
\hline $\begin{array}{c}\text { C.00.02.001 } \\
43\end{array}$ & 6 & $\mathrm{X}$ & $\sqrt{ }$ & $\sqrt{ }$ & $\sqrt{ }$ \\
\hline $\begin{array}{c}\text { C.00.02.001 } \\
43\end{array}$ & 7 & X & $\sqrt{ }$ & $\sqrt{ }$ & $\sqrt{ }$ \\
\hline $\begin{array}{c}\text { C.00.02.001 } \\
43\end{array}$ & 8 & A & $\sqrt{ }$ & $\sqrt{ }$ & $\sqrt{ }$ \\
\hline $\begin{array}{c}\text { C.00.02.001 } \\
43\end{array}$ & 9 & X & X & $x$ & $\mathrm{X}$ \\
\hline
\end{tabular}

Ket :

$\mathrm{x}$ : Tidak terbaca

$\sqrt{ }:$ Terbaca.

\section{Tahap Elaboration}

Pembuatan use case merupakan tahapan Elaboration berdasarkan hasil tahapan sebelumnya maka dapat dirancang sebuah use case aplikasi yang akan dibangun

Diagram use case merupakan diagram yang memodelkan aspek perilaku sistem. Masing-masing diagram use case memiliki aktor, use case, dan hubungannya. Pada sistem inventeris dan inventory terdapat tiga actor yaitu manajemen dan pelaksana. Aktor yaitu sebagai manajemen yang merupakan penyedia yang sudah terdaftar didalam sistem yang memiliki hak akses secara penuh untuk mengelola data monitoring dan laporan data barang secara berkala. Sedangkan dua actor yang selain sebagai pengguna yang memiliki hak akses terbatas sesuai dengan kebutuhannya. Pada actor pengguna terdapat actor turunan yang menjadi pengguna dalam system, dikarenakan yang terdaftar dalam system adalah fakultas sedangkan yang secara teknis melakukan kegiatan adalah Kepala Tata Usaha. Berikut Use Case Diagram yang diusulkan untuk aplikasi sistem inventeris dan inventory, yang ditunjukan pada gambar 5 dibawah ini. Use Case Diagram sistem inventeris dan inventory.

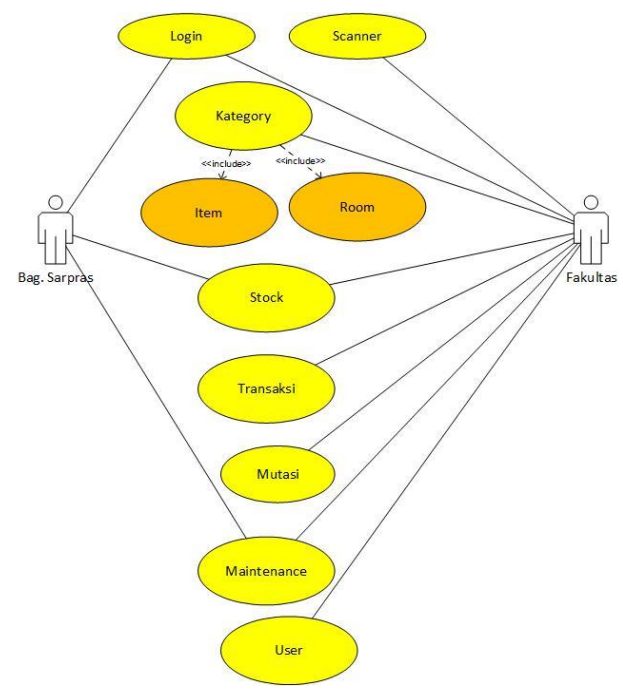

Gambar 5 Use Case aplikasi inventory

3. Tahap Construction

Tahap construction berisi tahapan pengimplementasian rancangan aplikasi perangkat lunak yang telah dibuat lengkap dan siap diserahkan kepada pemakai. Dalam tahapan construction dari metode RUP langkah-langkah yang dikerjakan adalah sebagai berikut.

Setelah dilakukan perancangan perangkat lunak dengan menggunakan use case diagram, maka selanjutnya melakukan pengembangan perangkat lunak system inventeris dan inventory dengan membuat perancangan antarmuka apilkasi berbasis web.

- Form login

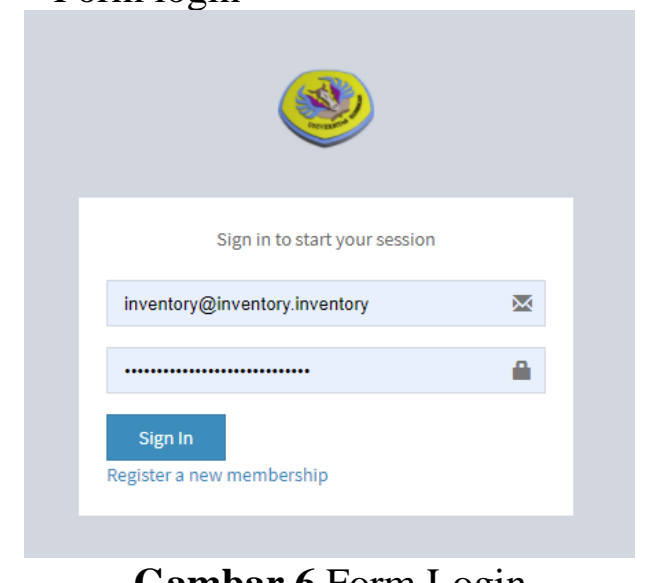

- Halaman menu utama 
JURNAL NUANSA INFORMATIKA

Volume 15 Nomor 1, Januari 2021

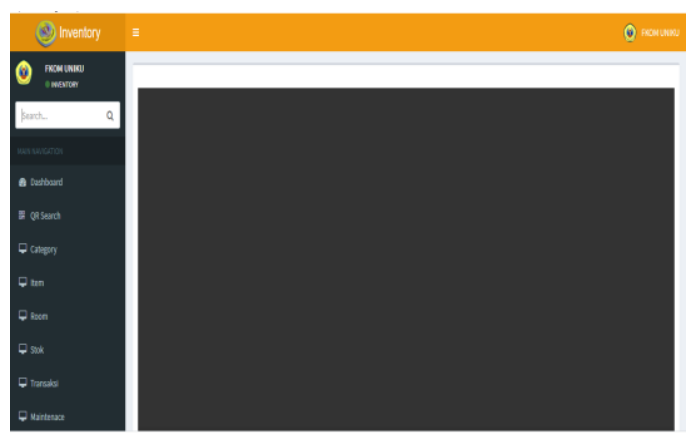

Gambar 7 Halaman Menu Utama

- Barcode search

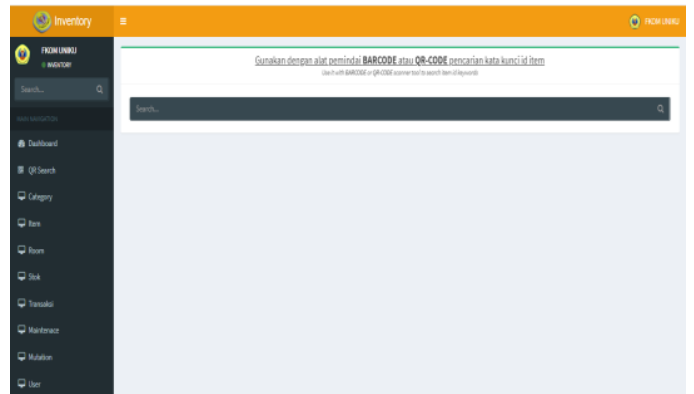

Gambar 8 Pencarian alat Barcode yang terhubung

- Proses scan

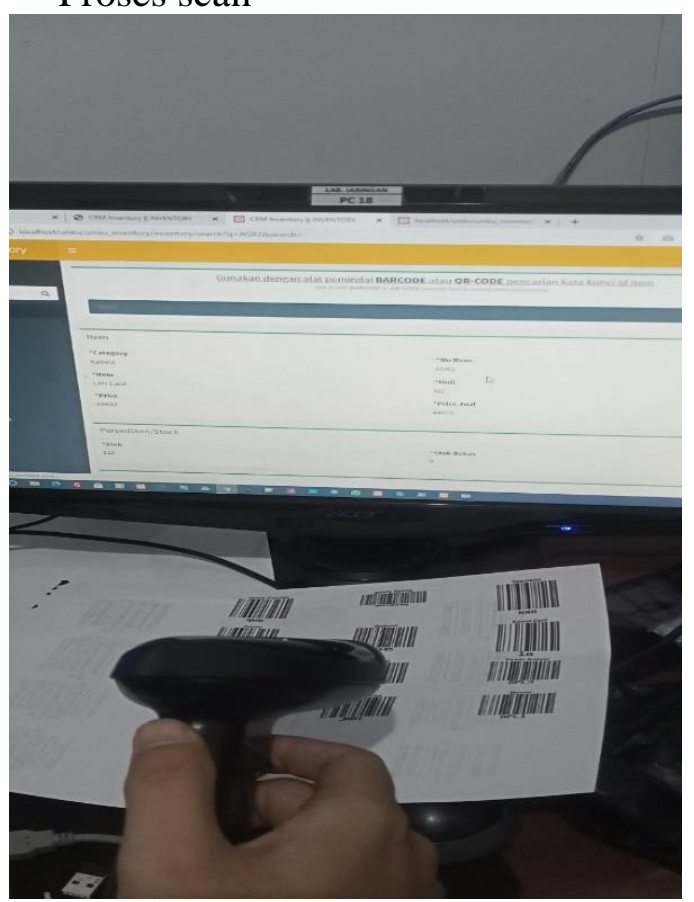

Gambar 9 Scan barcode
p-ISSN : 1858-3911, e-ISSN : 2614-5405

https://journal.uniku.ac.id/index.php/ilkom

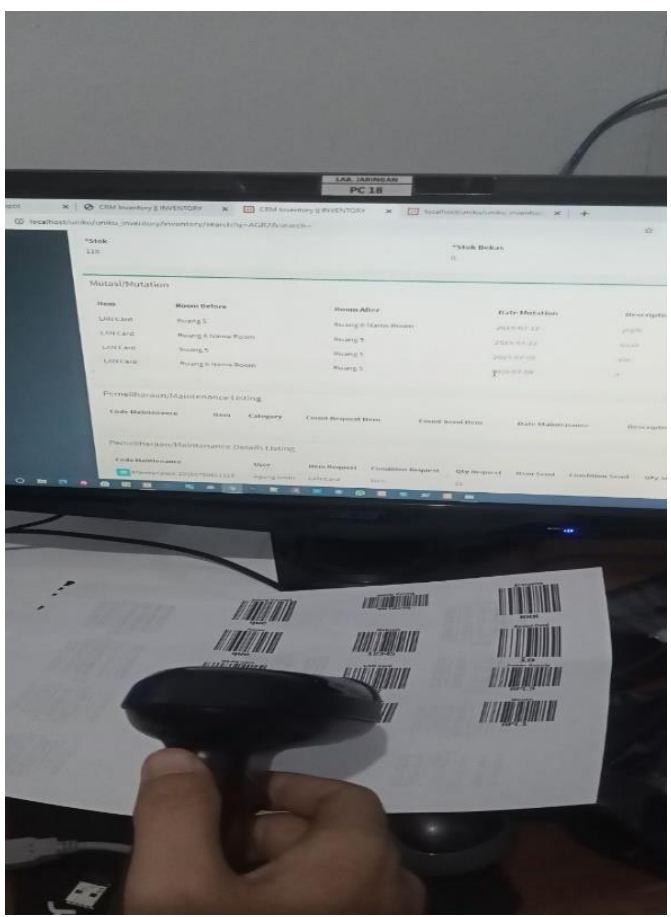

Gambar 10 Hasil Scan Barcode

- List barang dalam Categori Item

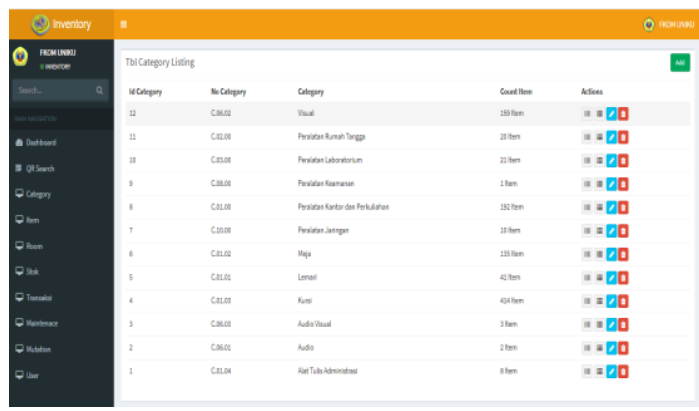

Gambar 11 Tabel Listing Categori Item

- Table category room

\begin{tabular}{|c|c|c|c|c|c|}
\hline 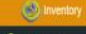 & " & & & & $0=0$ \\
\hline (2) naxumen & 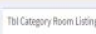 & & & & 口 \\
\hline En & ratesentant & 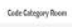 & amperanowions. & 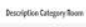 & tases \\
\hline 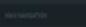 & w & 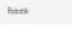 & 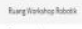 & 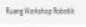 & 昰 \\
\hline antere & ' & $m$ & berestost & werents & 00 \\
\hline ascos & - & " & bysintions & basionion & 吅 \\
\hline ocong & $\mathrm{T}$ & $=$ & sentare & tortanes & 昰 \\
\hline $8 \mathrm{~m}$ & ' & 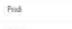 & is & nos & 吅 \\
\hline . & & nom & tandromisom & tentrats & 昰 \\
\hline vas & " & nex & rem & Limscion & 吅 \\
\hline Pas & & ston & besion & bexplater & 时 \\
\hline Plus & : & the & Hevosusen & -enimemen & 0 \\
\hline Promens & + & ua & иввои & Leatsunam & 吅 \\
\hline Onum & & & & & \\
\hline
\end{tabular}

Gambar 12 Categori room

- Item barang

- Hasil Scan 
JURNAL NUANSA INFORMATIKA

Volume 15 Nomor 1, Januari 2021

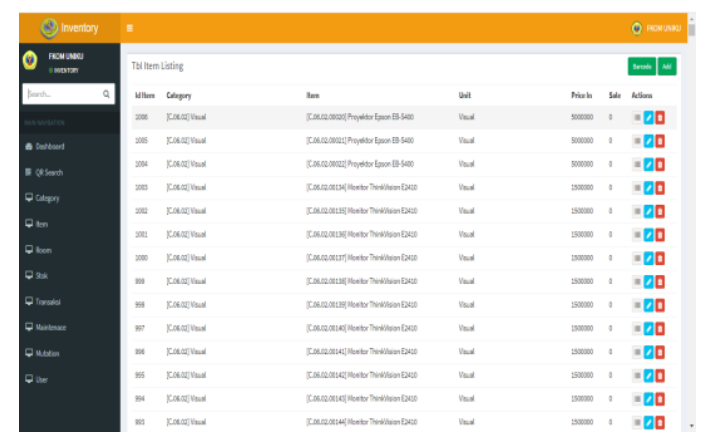

Gambar 13 listing Item barang

\section{- Item listing Room}

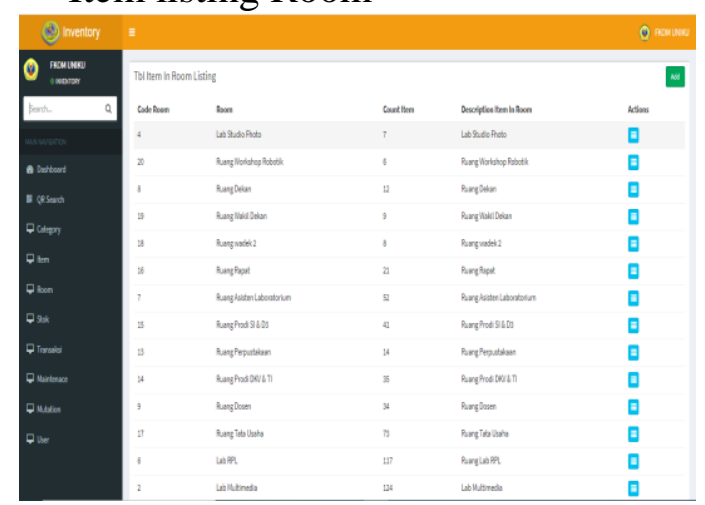

Gambar 14 item listing in Room

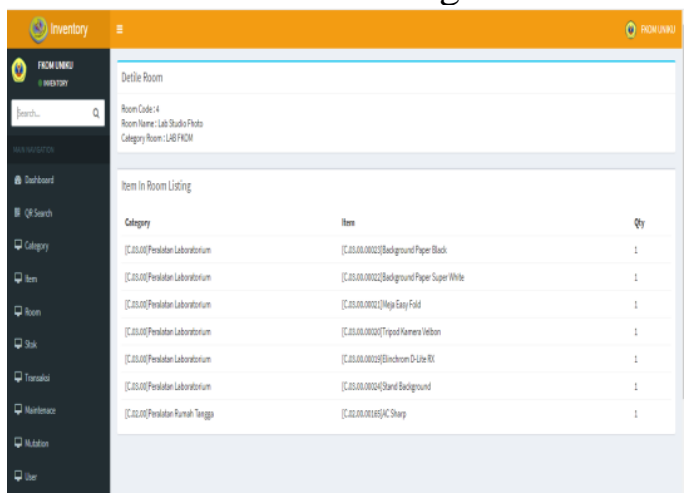

Gambar 15 detai item in room

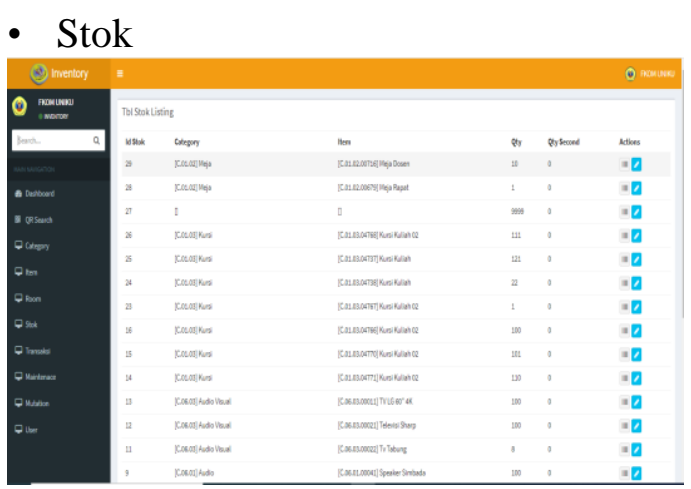

Gambar 16 stok item
p-ISSN : 1858-3911, e-ISSN : 2614-5405

https://journal.uniku.ac.id/index.php/ilkom

Berdasarkan hasil pengembangan

aplikasi yang dilakukan pada

penelitian ini dapat disimpulkan

bahwa

1. Pada aplikasi inventory ini fungsi

Barcode Scanner hanya dapat membaca kode barcode dan terkoneksi dengan aplikasi dapat memlalui hubungan kabel atau nir kabel.

2. Aplikasi ini dapat mempermudah proses pelacakan barang inventeris yang ada di fakultas yang disertakan dengan riwayat barang tersebut.

3. Proses pembuatan barcode masih dilakukan secara terpisah tidak secara otomatis dapat membuat barcode melalui alat scan.

4. Dengan menggunakan kode batang dapat dengan mudah ditempelkan dengan striker khusus untuk menjamin agar kode batang dapat bertahan lama dan tidak luntur atau buram.

5. Aplikasi ini harus terkoneksi secara simultan terhadap jaringan internet untuk dapat mengirimkan data real time.

\section{SARAN}

Berdasarkan hasil pengembangan aplikasi maka penulis menyarankan

1. Aplikasi ini dapat dikembangkan untuk mengelola data yang lebih besar dengan jaringan yang lebih stabil.

2. Aplikasi dapat dikembangkan kedalam versi mobile yang dapat mengenali aplikasi barcode scanner yang ditanam pada OS android.

\section{DAFTAR PUSTAKA}

[1] Nugroho.Adi. 2009. Rekayasa Perangkat Lunak Menggunakan UML \& Java. Yogyakarta: Andi Offset. 
JURNAL NUANSA INFORMATIKA

Volume 15 Nomor 1, Januari 2021
p-ISSN : 1858-3911, e-ISSN : 2614-5405

https://journal.uniku.ac.id/index.php/ilkom

[2] Hasan, V. C. (2016). Perancangan Sistem Informasi Inventori Darah Berbasis Web pada Palang Merah Indonesia Cabang Bantul . Journal Speed - Sentra Penelitian Engineering dan Edukasi , 35 - 41.

[3] A.S, Rosa. dan M. Shalahuddin. 2013. Rekayasa Perangkat Lunak Terstruktur dan Berorientasi Objek. Bandung: Informatika.

[4] I Yudha, M Sudarma, PA Mertasana. 2017. Perancangan Aplikasi Sistem Inventory Barang Menggunakan Barcode Scanner Berbasis Android - EJurnal Spektrum, 